\title{
Multi-temporal variation of the Ross Sea Polynya in response to climate forcings
}

\author{
Jinku Park ${ }^{a}$, Hyun-Cheol Kim ${ }^{b}$, Young-Heon Jo ${ }^{a}$, Autumn Kidwell $\mathbb{C}^{c}$ \& Jihyun Hwang ${ }^{\mathrm{a}}$

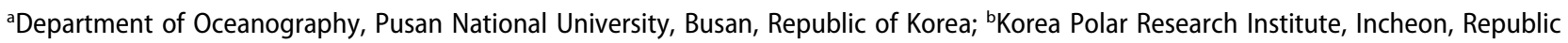 \\ of Korea; 'Applied Research Laboratories, The University of Texas at Austin, Austin, TX, USA
}

\section{ABSTRACT}

The multi-temporal scales of two physical characteristics (areas and occurrence time) of the Ross Sea Polynya (RSP) in Antarctica were analysed using a sea-ice concentration data set (1979-2014) derived from the Scanning Multichannel Microwave Radiometer, the Special Sensor Microwave Imager and Sensor Microwave Imager Sounder. Then, the Ensemble Empirical Mode Decomposition (EEMD) was applied to the data sets to decompose signals into finite numbers of intrinsic mode functions and a residual mode: long time trend. This approach allowed us to understand the long-term variability of the RSP area and occurrence in response to atmospheric forcing through teleconnections between low and high latitudes by comparing the Nino3.4 and Southern Annular Mode (SAM) indices. The nonlinear trend of the RSP areas derived from the EEMD residual had an upward trending shift in the early 1990s and was fairly consistent with the nonlinear trend of Nino3.4. However, the trend of RSP occurrence time progressively increased and had a significant effect on the long time scale. The trend of the RSP area is significantly correlated (+0.98) with the ratio of the trend of the meridional to zonal wind components related with the nonlinearity of Nino3.4, suggesting that meridional wind stress dominated the changes of the polynya area in the Ross Sea. In addition, the nonlinear trends between the SAM and RSP occurrence time show a strong positive correlation, contributing to the earlier onset of polynya expansion and delayed connection with the open ocean owing to enhanced southerly winds.

\section{KEYWORDS}

Ensemble Empirical Mode Decomposition (EEMD); nonlinear trend; Southern Ocean; sea ice; Antarctica

\section{ABBREVIATIONS}

EEMD: Ensemble Empirical

Mode Decomposition; ENSO:

El Niño-Southern

Oscillation; IMF: intrinsic

mode function; NASA:

National Aeronautics and

Space Administration; NCAR:

National Center for

Atmospheric Research;

NCEP: National Centers for

Environmental Prediction;

NSIDC: US National Snow

and Ice Data Center; RMSE:

root mean square error; RSP:

Ross Sea Polynya; SAM:

Southern Annular Mode;

SMMR: Scanning

Multichannel Microwave

Radiometer; SSM/I: Special

Sensor Microwave Imager

SSMIS: Sensor Microwave

Imager Sounder

\section{Introduction}

A polynya is a region of open water in the middle of the extensive pack ice found in polar regions. Polynyas can be classified into two categories based upon their location: open ocean polynyas and coastal polynyas. In particular, Antarctica has many coastal polynyas that contribute to changes in regional and global climates in various ways. Furthermore, polynyas affect bottom water formation (Comiso \& Gordon 1998; Jacobs 2004), synoptic weather systems (Zwally et al. 1985; Jacobs \& Comiso 1989; Montest-Hugo \& Yuan 2012), and high primary production (Arrigo \& Van Dijken 2003a). The Ross Sea (Fig. 1a) is an important area for polynya formation (Smith et al. 2007) and has the largest polynya in Antarctica, the RSP. During austral winter, the RSP narrowly stretches from the eastern side of Ross Island along the edge of the Ross Ice Shelf (Martin et al. 2007). In November, it begins to expand rapidly as the heat budget becomes positive (owing to the increasing sea-surface temperature caused by a seasonally intensified solar radiation), facilitating the melting of ice and reduction of ice formation. The polynya usually extends to the north-west and east, and by mid-January much of the continental shelf becomes ice free (Smith et al. 2007). The existence of the RSP is well reflected in the distributions of low sea-ice concentrations $(<60 \%)$ in the centre of the southern Ross Sea, as shown in Fig. 1b.

The formation and maintenance of the RSP are influenced by various forcing mechanisms. In particular, the wind stress pattern in the Ross Sea is one of the most significant forces related to the development of a RSP (Parish \& Bromwich 1987; Turner et al. 2009; Comiso et al. 2011; Drucker et al. 2011; Montest-Hugo \& Yuan 2012; Nihashi \& Ohshima 


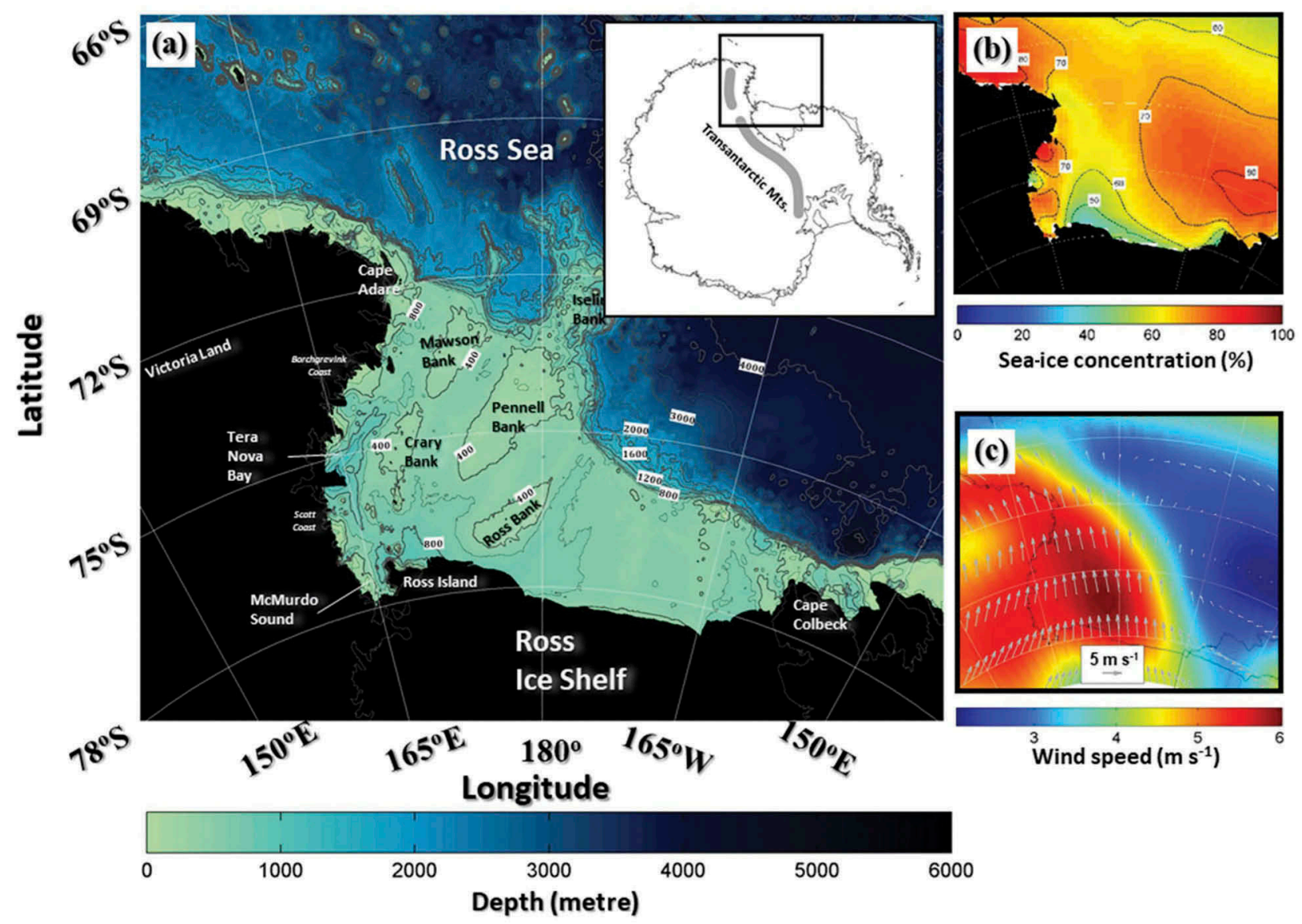

Figure 1. (a) Maps of the Ross Sea, Antarctica. The colour scale indicates the bathymetry, (b) The climatology of sea-ice concentration (in terms of percentage of ice coverage) in the Ross Sea from 1979 to 2014, (c) The climatology of $10 \mathrm{~m}$ wind fields during the years derived from the NCEP/NCAR reanalysis data sets for the same time periods. The colour scale background represents wind speed.

2015). The RSP is mainly formed and maintained by strong drainage flows driven by the katabatic winds off the Transantarctic Mountains (Fig. 1c). The southerly wind stress is responsible for decreasing the sea-surface temperature that reach the freezing point, introducing new sea-ice growth. The new ice is, in turn, pushed away from the coast to the north by the katabatic winds (Arrigo \& Van Dijken 2003a; Petrelli et al. 2008; Ruciano et al. 2013). Accordingly, this mechanism plays a role in keeping the RSP open for entire seasons (Bromwich et al. 1998). During this process, latent heat is released into the atmosphere (Van Woert 1999).

The variation in sea ice in the Ross Sea is often associated with the ENSO (Bromwich et al. 1998; Arrigo \& Van Dijken 2003a; Turner et al. 2009). Bromwich et al. (1998) showed that the interannual variation of the RSP is associated with the atmospheric forcing on synoptic scales. Their results showed that atmospheric circulation in the high latitudes of the Southern Hemisphere could be changed by an anomalous low-pressure system induced by ENSO-related activity. In addition, Arrigo \& Van Dijken (2003b) found that the spatial size of the RSP from 1992 to 2001 was related to changes in the climate state, as expressed with the multivariate ENSO index using linear regression. They concluded that $76 \%$ of the interannual variation in the sea-ice extent between 1992 and 2001 could be explained by the multivariate ENSO index, particularly during the 1997-98 El Niño year, which exhibited the greatest sea-ice cover, but the 1999-2000 La Niña year showed the small sea-ice extent. According to Turner et al. (2009), the wind system in Ross Sea has changed owing to a modification of the Amundsen Sea Low. Once the Amundsen Sea Low is deepened, southerly winds over the Ross Sea are likely to be reinforced. In contrast, a weakening Amundsen Sea Low could attenuate the southerly winds. The depth of the Amundsen Sea Low is closely associated with the phase of ENSO (Turner et al. 2009). During the La Niña phase, the low is deeper than during the El Niño warm phase.

Most previous studies have heavily relied on a simple linear trend analysis to explain polynya dynamics or analyse sea-ice changes. This is a good approach to understand variation trends; however, it cannot show the processes of variation and may lead to misinterpretations in analysing long time scale variation (Franzke 2012). To overcome this problem, 
a new approach, which is detailed herein, was applied to investigate the long-term variability of the RSP. Two physical RSP parameters-area and occurrence times-were analysed. The objectives of this research were as follows: (1) update information on the variation in physical characteristics of the RSP in terms of size and occurrence time; (2) understand how polynya features have been changed based on conventional linear and nonlinear trends; and (3) identify the effect of forcings on RSP development and compare RSP variability with a few climate indices to ascertain RSP's response to synoptic climate patterns.

\section{Data and methods}

\section{Data}

To identify polynyas, sea-ice concentration data derived from the SMMR, the SSM/I and the SSMIS passive microwave radiometer were used. The data set was provided by the NSIDC (Cavalieri et al. 1996). Although the SMMR ice-concentration data are available at a temporal resolution of two days, the SSM/I and SSMIS data sets contained daily temporal observations. All three data sets have a $25 \mathrm{~km}$ spatial resolution and can be used successively from January 1979 to December 2014. The sea-ice concentration from brightness temperature was calculated using the NASA Team sea-ice algorithm, which was developed by NASA's Goddard Space Flight Center and produced by NSIDC (Cavalieri et al. 1996).

To investigate the variation of winds on a time scale longer than one year, which is the most important physical factor for the formation and maintenance of the RSP (Bromwich et al. 1998; Van Woert et al. 2003), the NCEP/NCAR reanalysis product was used. The NCEP/NCAR reanalysis project was launched in 1991 to produce a retroactive record of more than 50 years of global analyses of atmospheric fields to support the needs of the research and climate monitoring communities (Kalnay et al. 1996; Kistler et al. 2001). It provides monthly means of a variety of variables from 1948 to the present with a $2.5^{\circ}$ spatial resolution. To produce a time series of the wind components, the data were spatially averaged (longitude $165^{\circ} \mathrm{E}$ to $165^{\circ} \mathrm{W}$ and latitude $73^{\circ} \mathrm{S}$ to $79^{\circ} \mathrm{S}$ ).

\section{Climate indices}

In addition, some climate indices were adopted in the decomposition method to better understand the variability of area and occurrence time in the response of polynyas to the global climate state. To compare the characteristics of the RSP variability and climate indices, the following steps were performed. (1) The EEMD was employed to best-known climate indices, such as the Southern Oscillation Index, the
East Central Tropical Pacific sea-surface temperature index (Nino3.4) and the SAM, and the multivariate ENSO index obtained from the Joint Institute for the Study of the Atmosphere and Ocean at the University of Washington. It was assumed that if the long-term trends of each data set showed a similar pattern, the potential long-term variability of the data would be controlled by similar physical processes. (2) The long-term trends of each climate index to the polynya area and occurrence time were compared. (3) The climate indices whose trends fit well with those of the polynya area and occurrence time were selected to describe the response of the RSP to the climate state. Furthermore, a comparative analysis was conducted to identify the relation between the components of the interannual and decadal variability of the polynya and climate indices. In advance, the Nino3.4 and SAM indices were used for the comparison (Fig. 2). The nonlinear trend of the polynya area was completely consistent with that of Nino3.4 or Southern Oscillation Index, which are well-known indicators of ENSO. Trends longer than a decadal time scale of the RSP occurrence time probably depend on the physical processes that are characterized by SAM through the residual of the SAM index.

\section{Determination of a polynya boundary}

Before extracting both characteristics (size and occurrence time) of the RSP, the boundaries of the RSP must be determined. In this analysis, 15\% sea-ice

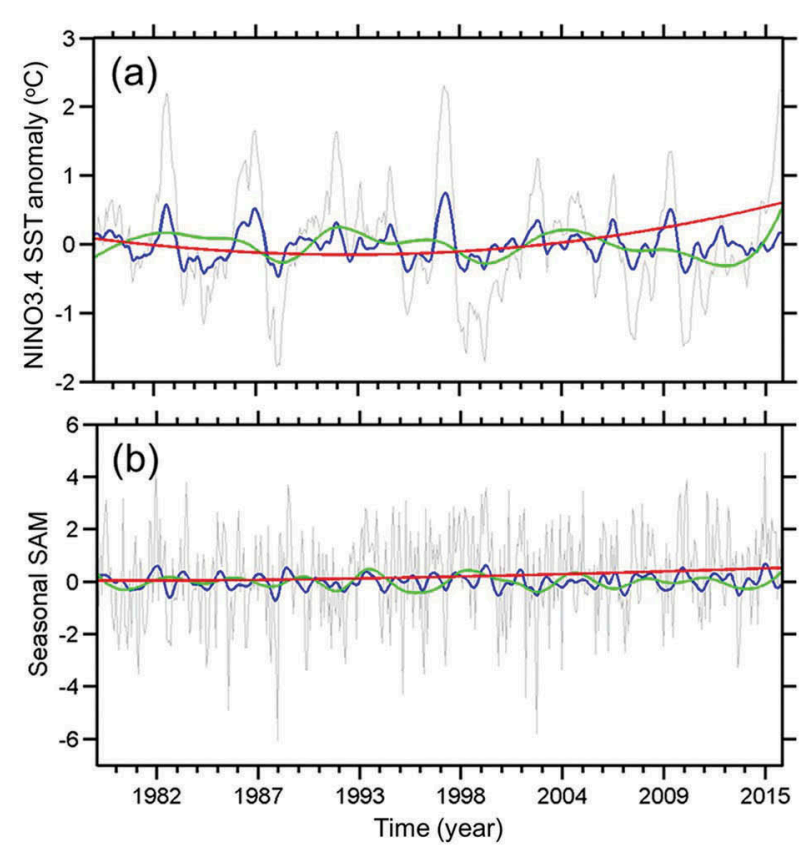

Figure 2. Monthly time series of the (a) Nino3.4, and (b) SAM indices from 1979 to 2014. The blue and green solid lines show the interannual and decadal components estimated by EEMD, respectively. The red line indicates the residual, representing the trend of the original time series. 
concentrations, which is a criterion of a marginal ice edge (Sea Ice Atlas 2015), were selected as polynya boundaries.

The area was calculated by selecting the grid points with an ice concentration of at least 15\% and summing the geographical areas of all grids within the boundary. Finally, the entire area of the polynya was estimated by adopting the data array that contains the areal values for individual cells in the $25 \mathrm{~km} \mathrm{SSM/I} \mathrm{polar} \mathrm{stereographic} \mathrm{grids.}$ This array (produced as an ASCII file named pss25area.dat) is currently available at the NSIDC website (NSIDC 2015). The occurrence time of the polynya is defined as the period between the onset and end of polynya development. The onset of polynya development was determined as the first moment when a grid with less than $15 \%$ sea-ice concentration (Sea Ice Atlas 2015) in the southern Ross Sea can be detected in the sea-ice concentration data. In addition, the termination was defined as the time when the polynya is completely opened to the Southern Ocean. Using these definitions, the daily product of the changes of polynya size and yearly data on the occurrence time of the polynya (time of connection minus time of onset) was constructed and analysed in this research.

\section{EEMD}

Conventionally, ordinary least squares (linear regression) is used for trend estimation in climate research (Franzke 2012) and for many studies of sea ice, particularly in the polar regions (Arrigo \& Van Dijken 2003a; Comiso et al. 2011; Drucker et al. 2011). Although linear regression can intuitively show the variability of time series, it contains no information about the process of variation during the entire observational period. The method can therefore lead to the misinterpretation of processes in nature, which can be nonlinear and nonstationary (Franzke 2012).

Nevertheless, linear regression was used to identify a linear variability for insight into the long-term change of the RSP and a decomposition method was employed to extract a cyclical signal from the original time series. Several well-known decomposition methods such as the empirical orthogonal function and singular spectral analysis decompose a given time series into reconstruction components for given time scales. These methods are suitable for decomposing signals with constant periodicity, but they do not perform any analysis on residual components (i.e., only periodic signals are extracted). Therefore, their results completely depend on a span of data. In fact, if the variability is dominated by a further long periodic component, such methods might be inappropriate. The approach in this study has the feature of extracting the periodic component like other decomposition techniques while also leaving the residual component, which is no longer decomposed (i.e., not cyclical).

To analyse nonstationary and nonlinear time series data, the Hilbert-Huang Transform (Empirical Mode Decomposition + Hilbert-Huang Spectrum) method introduced by Huang et al. (1998) was used. The method is based on the simple assumption that all data comprise different simple intrinsic oscillatory modes that have individual physical meanings (Lee 2013). EEMD is an improved version of EMD that resolves a problem with EMD: mode mixing (Wu \& Huang 2004; Jo et al. 2014). The EEMD method decomposes a time series into a finite number of IMFs) and a residual monotonic function through a sifting process (Huang et al. 1998; Wu \& Huang 2004; Franzke 2012). The sifting process is performed as follows: (1) local maxima and minima are identified in the original time series; (2) a lower (upper) envelope is estimated by fitting cubic splines to the local minima (maxima); and (3) the first IMF, $c_{1}$, is calculated by subtracting the mean of the envelopes, $m_{1}(t)$, from the original time series, $x(t)$ :

$$
c_{1}=x(t)-m_{1}(t) .
$$

Once the first IMF has been obtained, it is subtracted from the original data, which produces residuals:

$$
r_{1}=x(t)-c_{1}(t)
$$

The second IMF can be calculated from the residuals and the first IMF as:

$$
c_{2}(t)=r_{1}(t)-i m f_{1}(t) .
$$

This process is then repeated until the residuals satisfy two stopping criteria: (1) the number of zero crossings and envelopes are equal or differ by at most one; and (2) the mean value of the envelopes is zero (Capparelli et al. 2013; Lee 2013). Consequently, the original time series can be stated as:

$$
x_{t}=\sum_{i=1}^{n} c_{i}+r_{n},
$$

where $n$ denotes the number of IMFs and $r_{n}$ represents the residual mode corresponding to a nonlinear trend. For more information on EEMD, refer to the descriptions in $\mathrm{Wu} \&$ Huang (2004) and $\mathrm{Wu}$ \& Huang (2009). A conventional application of EEMD is typically 100 independent trials in the ensemble (Wu et al. 2009) and the criterion was applied equally in this analysis. To examine the significance level of the residuals, the bootstrap method was employed as demonstrated by 
Mudelsee (2010), Ezer \& Corlett (2012) and Jo et al. (2016) (Supplementary material).

The dynamical processes of RSP variations are difficult to succinctly study because of the complex nature of the various forcings (Smith \& Barber 2007) and the rapidly changing climate. This is, therefore, challenging. Consequently, the decomposition method might be essential to the analysis of polynyas in this region. Because each of the IMFs has an intrinsic physical meaning, assessing the extent of the physical factors that affect polynya development is helpful. In this analysis, trends in the changes of polynya areas and occurrence times derived from sea-ice concentration data were investigated using this method to identify the long-term temporal variability in the RSP over a long time scale.

\section{Results and discussion}

\section{The RSP from 1979 to 2014}

A series of seasonal mean sea-ice distributions shows that the RSP experiences large annual variations (Fig. 3). It extends to the north while retaining a large east-west width adjacent to Cape Colbeck (approximately $150^{\circ} \mathrm{E}$ ), which serves as an eastern boundary
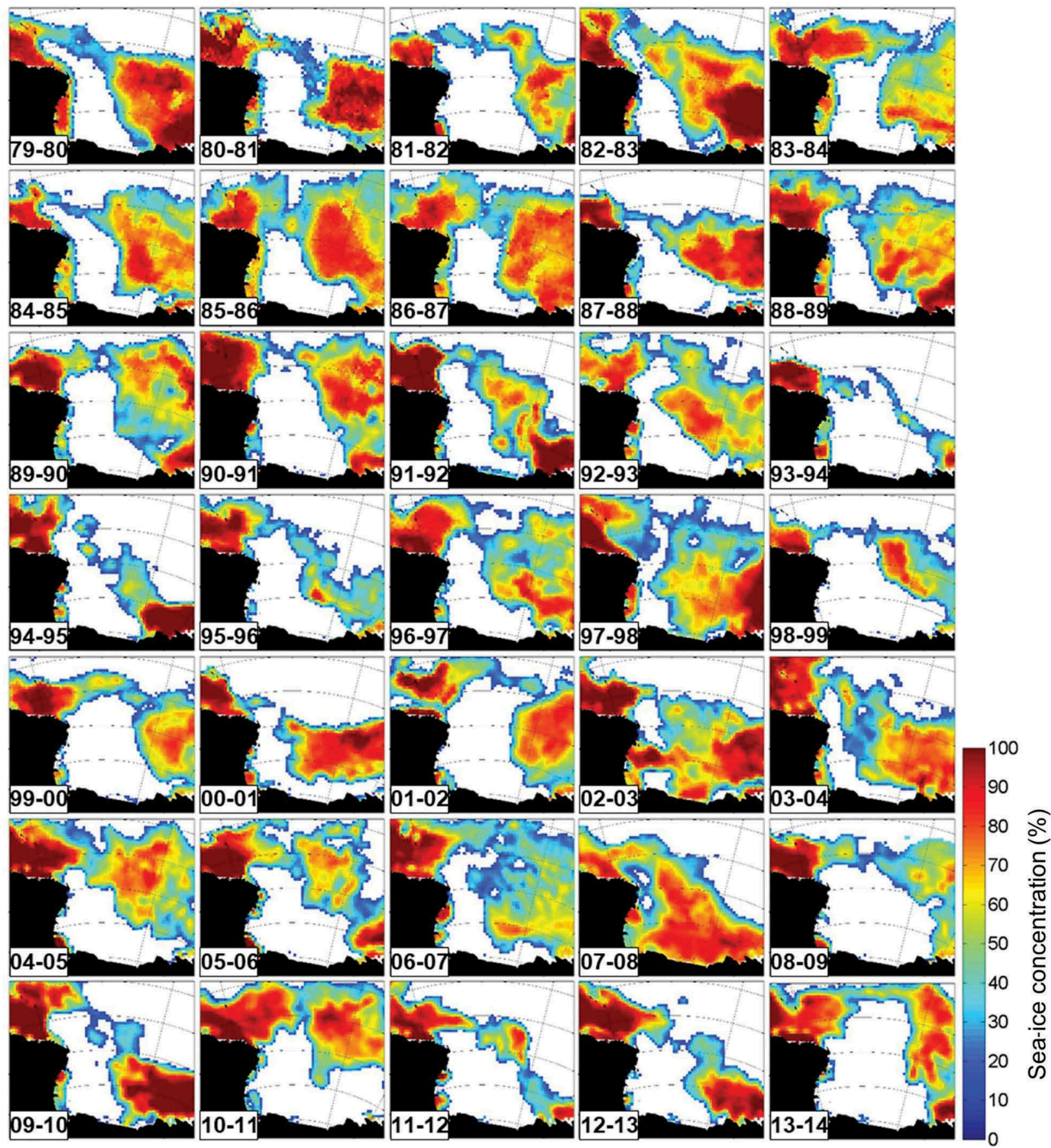

Figure 3. Maps of sea-ice concentration in percentages during austral summers. The polynya boundary was determined as $<15 \%$ of the sea-ice concentration (NSIDC 2015). 
(e.g., 1993/94, 1998/99 and 2013/14), and narrow hornshaped polynya are occasionally formed along the coast of the western Ross Sea (e.g., 1997/98, 2000/01 and 2003/04). The recent large polynyas in 1998/99 and 2013/14 covered most of the continental shelves and stretched to Cape Colbeck. Regarding the narrow polynyas, the polynya in 2000/01 is L-shaped and may have been caused by the iceberg fragments (B-15B and a few other fragments) that formed fast ice on the eastern sides of the icebergs (Arrigo et al. 2002). In addition, during the 2002/03 austral summer (November to February), two small polynyas developed off Cape Adare $\left(172^{\circ} \mathrm{E}, 72^{\circ} \mathrm{S}\right)$ and in part of the western Ross Ice Shelf (i.e., north of Ross Island; $170^{\circ} \mathrm{E}, 77^{\circ} \mathrm{S}$ ). They arose owing to the effects of icebergs B-15A and C-19 (Robinson \& Williams 2012).

\section{Multi-temporal change of the RSP areas}

To better understand the variability of RSP area, the time series of RSP areas are shown in Fig. 4. The annual data was determined as a maximum area of the RSP before the polynya connected with the open ocean. The minimum area of the RSP over the discrete austral summer was approximately $94697 \mathrm{~km}^{2}$ during the 2002/03 austral summer, followed by the small polynya in the $1997 / 98$ austral summer, which had an area of $149269 \mathrm{~km}^{2}$. The largest RSP area was approximately $836590 \mathrm{~km}^{2}$ on 14 January 2014, during the 2013/14 austral summer. It was 3.96 times larger than the mean area-211 $130 \mathrm{~km}^{2}-$ over the span of this research. Overall, the polynya area time series shows significant interannual fluctuation, and there are especially large fluctuations during the late 1990s and early 2000s. In addition, the RSP has grown rapidly since the mid-2000s. Overall, the total variation in the RSP area tends to increase linearly (about $1487.70 \mathrm{~km}^{2} \mathrm{yr}^{-1}$ ) as shown by the ordinary least square fitting on a long time scale. However, such a slight linear increase in the area estimated by the first-order regression could be unreasonable because a glance at the pattern from the beginning of the observation to the late 1990s shows a decreasing trend. When performing a second-order regression analysis, the area shows an increasing pattern after declining in the mid-1990s. Actually, the $\mathrm{R}^{2}(0.12)$ of the second-order regression result is fairly higher than that of the first-order regression (0.01), and the RMSE is decreased (from 171900 to $164800 \mathrm{~km}^{2}$ ). This shows that the second-order regression is more appropriate than the first-order regression for the trend of RSP areas. On the second-order regression trend of RSP area, the variation of RSP areas shows an increase between about 1979 and 1995 and a decrease between 1995 and 2014. First, given the linear increase of polynya areas estimated by linear regression, an increase in polynya areas can be expected to be possible during years of higher sea-ice extent. In fact, Comiso et al. (2011) reported that the sea-ice concentration in the Ross Sea has increased as much as $0.028 \% \pm 0.016 \% /$ year from 1978 to 2008, as derived from a linear regression of anomaly data in their research. In addition, increases of sea-ice extent in the Ross Sea continue to be reported by many researchers (Liu et al. 2004; Turner et al. 2009; Parkinson \& Cavalieri 2012).

In addition to simple regression analysis, the multi-temporal variability of RSP areas, including periodic components and a nonlinear signal for the areas, was investigated using EEMD. A significance test on the cyclic components (IMFs) was conducted to identify whether the individual IMFs of the polynya area were statistically significant (Fig. 5). The components with periods shorter than a year (i.e., high frequency) were disregarded

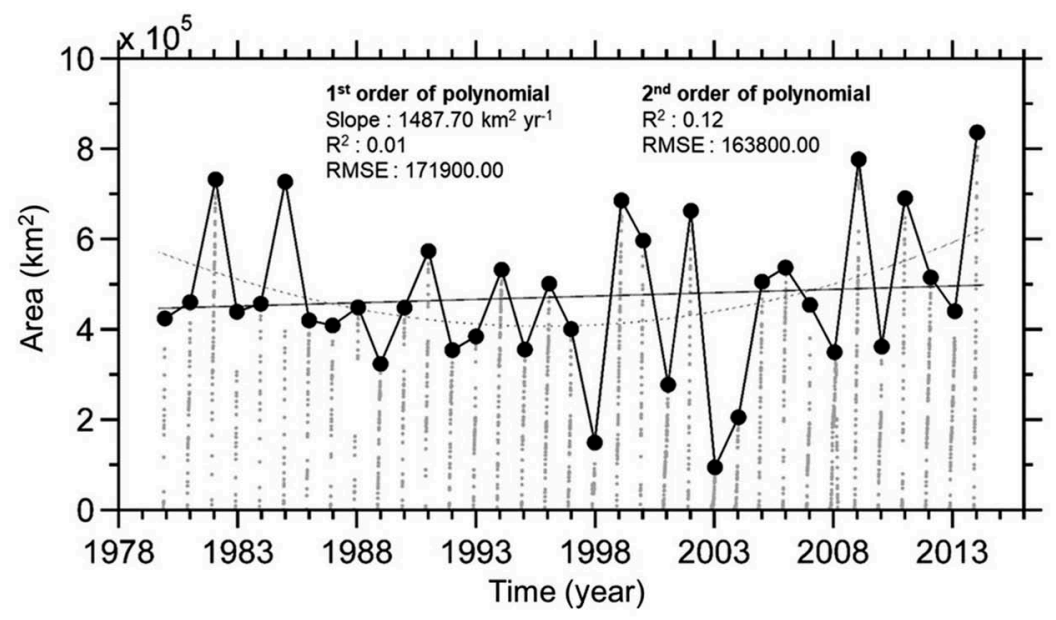

Figure 4. The variation of the RSP areas evaluated for grids of the open ocean regions (grey dots). Black dots represent the maximum areas in each austral summer. The solid and dashed lines are the first- and second-order regression curves, respectively. 


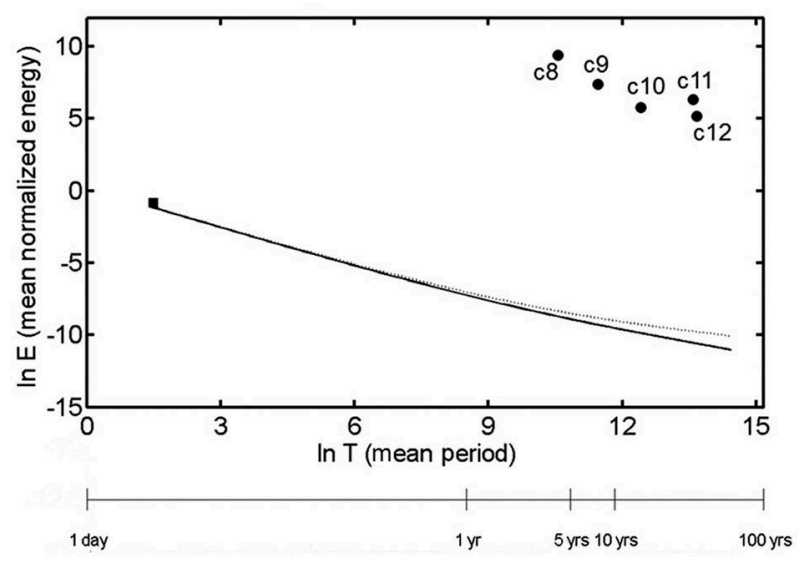

Figure 5. A significance test of the result of EEMD for the RSP area. The solid and dotted lines are spread functions that represent the $95 \%$ and $99 \%$ confidence levels, respectively. The results of the test on the IMFs with a long period more than one year (c8-c12) are illustrated as black circles.

in this research. Owing to the characteristics of the polynya that is formed only during the austral spring and summer, components with a period of less than one year are likely to be noise, and the interpretation of this noise could lead to failure of the analysis. Therefore, components with short mean periods that are less than a year were not considered in the analysis of RSP variation. The EEMD analysis on the RSP area conclusively yielded 12 oscillatory modes, c1-c12. Based on the sifting process to determine IMFs, each IMF energy density is above the spread function, which is considered statistically significant at the selected confidence level (Lee 2013). Among the IMFs with low frequencies, i.e., periods of more than one year, c8 has a high mean energy density after $\mathrm{c} 9$. While the mean period of $c 8$ was approximately 4.1 years, that of $c 9$ was about 7.7 years. In sequence, the energies of $c 10, c 11$, and $c 12$ were less than those of $\mathrm{c} 8$ and $\mathrm{c} 9$, and the corresponding mean periods of those modes were 14.8, 33.8, and 35.5 years, respectively. Overall, this shows that the low-frequency components were decomposed well from the original signal. Furthermore, they could have their own unique physical meaning for the analysis and could be interpreted as trends within certain periods.

The residual mode of the variability in RSP area in the austral summer (Fig. 6) has only one local minimum, and a change in the trend is observed in the early 1990s. Such changing points are called "turning points" in this study. For the significance of residuals estimated from the polynya areas, the bootstrap method was employed (see the Supplementary material for details). Despite the iterative analysis through random sampling, the turning point appears in the early 1990s, which is similar to the previous results, and the lag is less than one year.

To prove the existence of the 1992/93 turning point, the regional distributions of the linear trend in sea-ice concentration before and after 1992/93 in the Ross Sea are estimated (Fig. 7). During

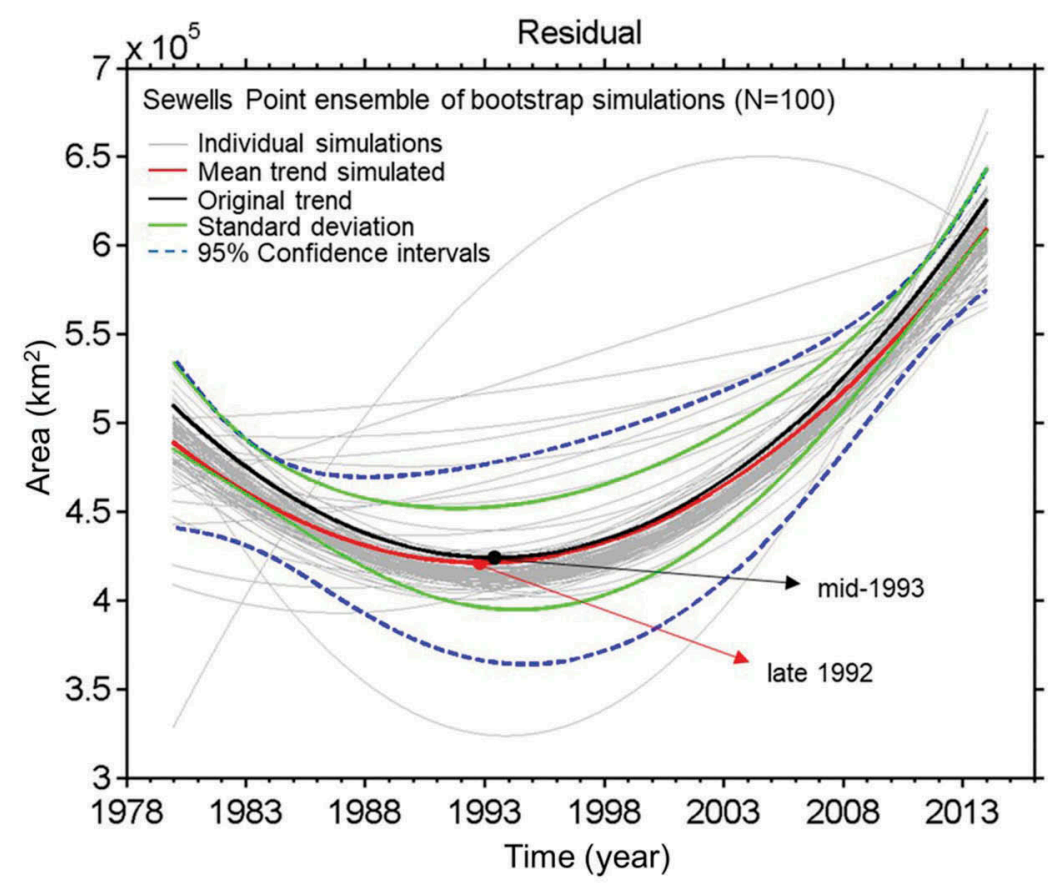

Figure 6. Time series of the residual mode of the RSP areas extracted by EEMD with bootstrap simulations (100 iterations) for the significance test. The solid grey lines indicate the simulated individual trends, and the red and black lines are the trends of the artificial mean and original data, respectively. The standard deviation and the $95 \%$ confidence intervals are expressed as the green solid lines and blue dashed lines, respectively. The red and black circles indicate the turning points of each trend. 

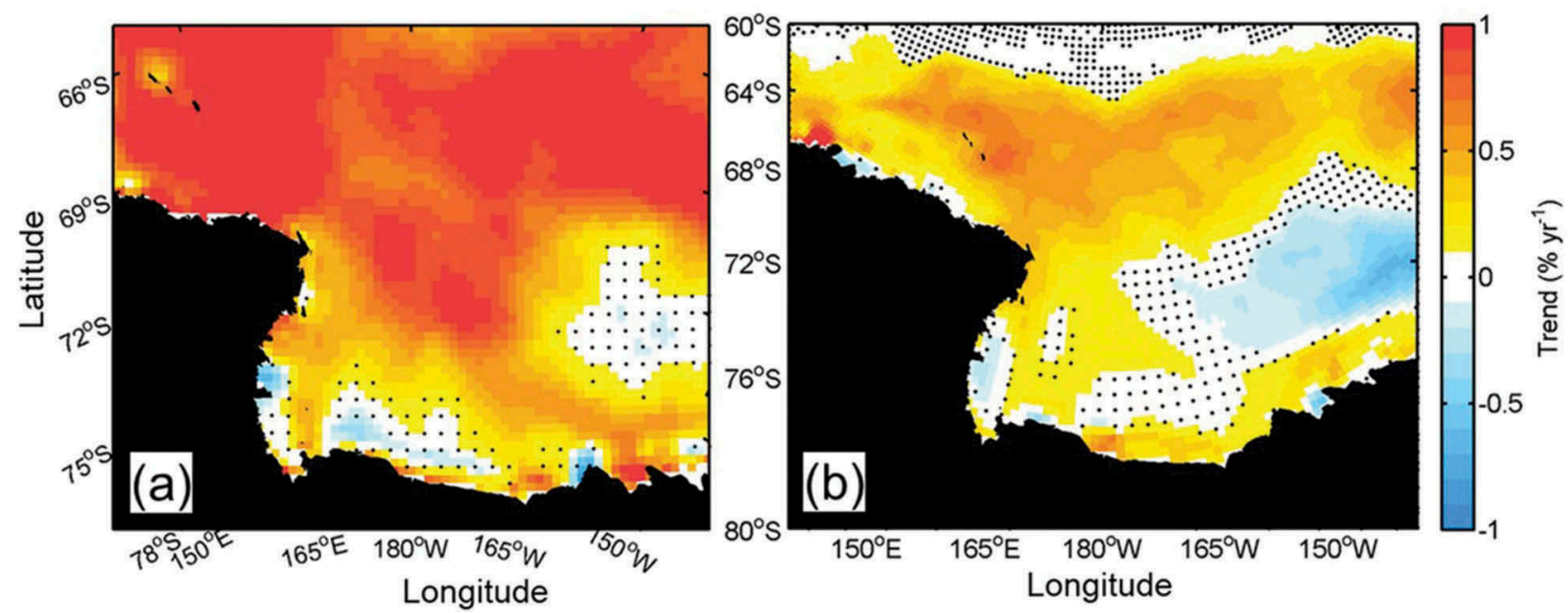

Figure 7. Maps of the linear trend of sea-ice concentration (a) in 1979-1992 and (b) 1993-2014; there was a phase change in the residual mode of the RSP area in 1992/93. Stippled points indicate regions with a statistically insignificant trend $(p>0.05)$.

1979-1992, the linear trend of ice concentration shows a larger positive trend $(2 \%-4 \%$ per year) far away from the Ross Sea coast, whereas the ice concentration along the Ross Ice Shelf decreases with a trend of about $0.5 \%$ per year or less. Moreover, around Terra Nova Bay, sea ice has steadily declined with a trend of more than $0.5 \%$ per year. On the other hand, trends of sea-ice variation from 1993 to 2014 show an overall increase in the southern Ross Sea, especially in areas adjacent to the Ross Ice Shelf, at $0.5 \%$ per year. Although the sea ice around Terra Nova Bay tends to decrease as in the previous period, the rate of decline is reduced (negative $0.1 \%-0.2 \%$ per year). In the offshore case, the rate of increase was also slower than in the previous period $(<0.5 \%$ per year). As a result, these trends of ice concentration in the area support the residuals calculated by the EEMD, and this could be evidence that polynya variability in the southern Ross Sea has changed since 1992/93.

Wind could be considered as the major factor for polynya development (Zwally et al. 1985; Comiso et al. 2011; Drucker et al. 2011). In this study, the relation between the wind responsible for RSP dynamics and several climate states is evaluated by estimating the nonlinear long-term variability in the winds linked with ENSO. The residuals of both the meridional and zonal wind components obtained
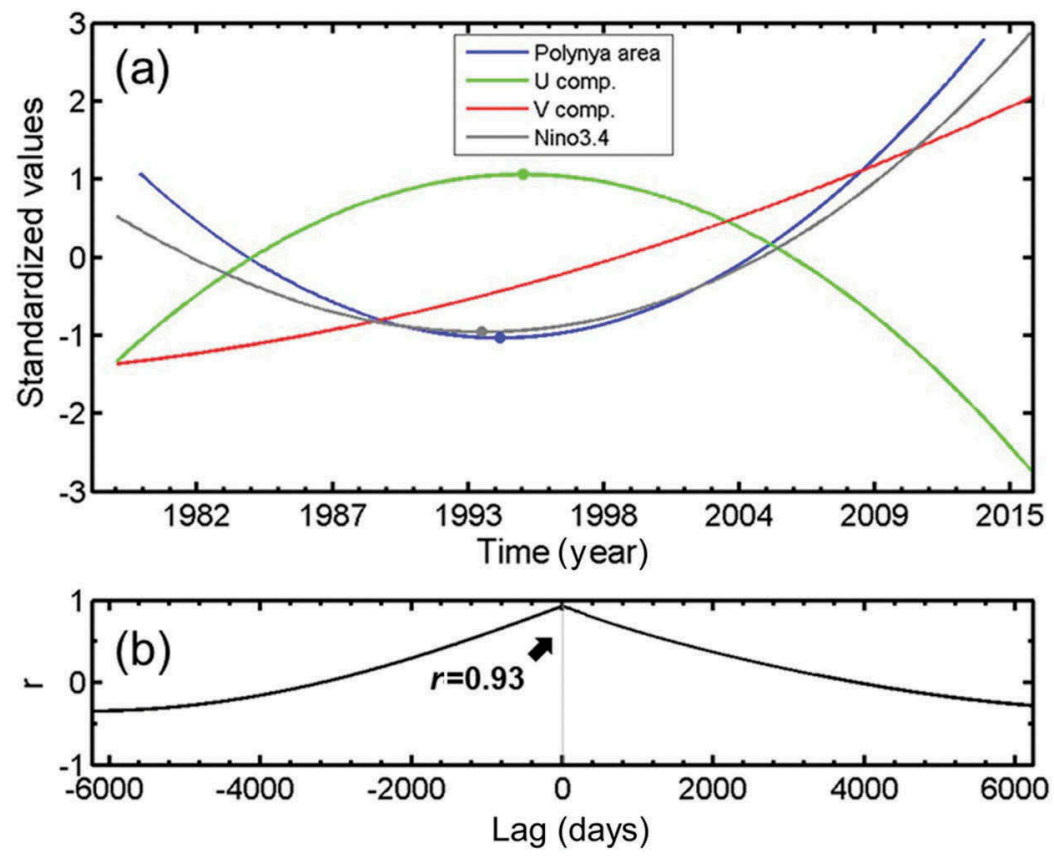

Figure 8. (a) The standardized nonlinear trends of the RSP area (blue), meridional (red) and zonal (green) wind components, and the Nino3.4 (grey), (b) The cross correlation between the normalized trend of the RSP areas and the ratio of wind components (meridional/zonal). 
from NCEP/NCAR reanalysis data over the southern Ross Sea $\left(165^{\circ} \mathrm{E}-165^{\circ} \mathrm{W}, 80^{\circ} \mathrm{S}-70^{\circ} \mathrm{S}\right)$ were calculated using EEMD and then compared with the nonlinear trend in the RSP area. This identified how polynya area evolution responded to alterations of the wind system (Fig. 8a). In addition, the nonlinear trend of the Nino3.4 index was examined to address its relation with the nonlinear trend of the wind system over the Ross Sea and the RSP areas. Notably, the nonlinear trend of the variability in the north-south (meridional) component tends to gradually increase during the span of this research and has no direct relation to the polynya area trend. However, the residual mode of the zonal wind component indicated a strong negative relation, and the timing of when the turning point occurred in the residual of zonal wind component is similar to that in the residual of the RSP area (Fig. 8a).

For the RSP, the meridional wind components dominate in the southern Ross Sea during the austral spring and summer when the RSP is expanding, as shown in Fig. 1c, and the residual of the zonal component shows an opposite pattern to the residual of the RSP area. Therefore, we were able to assume that the zonal and meridional winds, on a long time scale, are the limiting and developmental factors for RSP expansion, respectively. To quantitatively determine the influence of the wind on the nonlinearity of RSP development, the correlation between the ratio of the residual modes of the zonal and meridional components (the residual mode of the meridional wind divided by the zonal one) was estimated (Fig. 8b). They have a fairly close relation, with a high correlation coefficient of 0.93 at zero lag. As reported by Nihashi \& Ohshima (2015), RSP development has a strong connectivity with southerly winds, especially when the wind blows in the direction of $213^{\circ}$. These winds cause divergent ice motions away from the coastline. The polynya areas around the Terra Nova Bay have the highest correlation $(r=0.50)$ with westerly winds $\left(276^{\circ}\right)$, but it is unlikely to have a significant impact on the entire Ross Sea owing to its small size. The time series of the wind components in the southern Ross Sea between 1979 and 2014 (Fig. 9) shows a strong decadal variability in both the zonal and meridional wind components. However, the trend of the zonal component estimated by the secondorder regression shows a similar pattern to the residual of zonal component, but the signal is fairly weak owing to strong decadal components. The second-order trend of the meridional wind component is also similar with the residual of meridional component, which increases gradually.

Efforts to identify the changes in the sea-ice concentration in the Antarctic, including the Ross Sea, and its relation with climate indices such as ENSO and SAM,
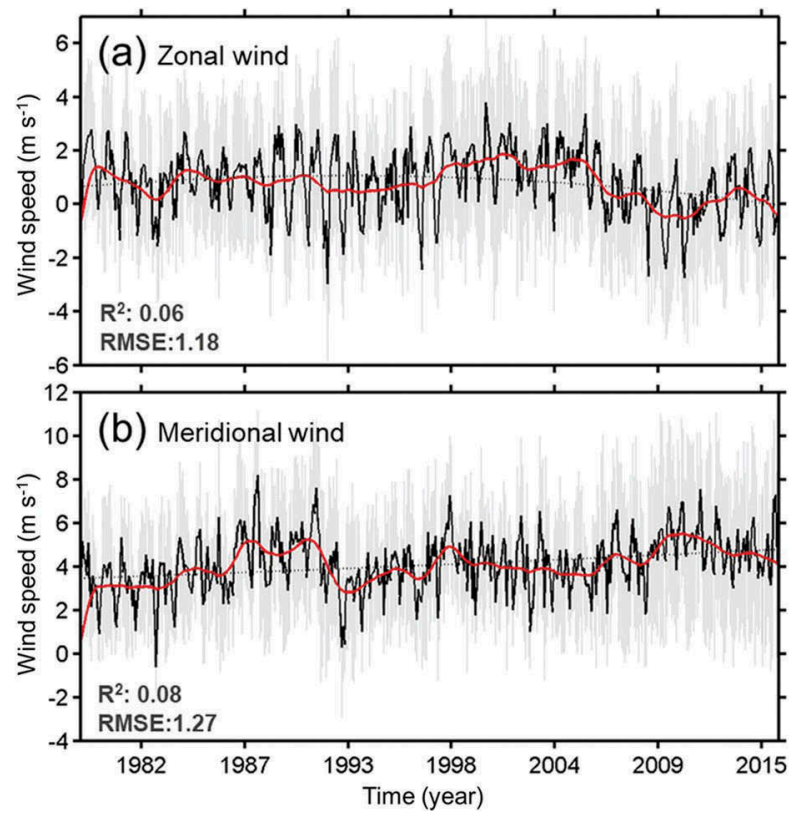

Figure 9. The spatially averaged (a) zonal, and (b) meridional wind speed between 1979 and 2015. The grey patches indicate the range of wind speed over the area $\left(165^{\circ} \mathrm{E}-165^{\circ} \mathrm{W}, 73^{\circ} \mathrm{S}-79^{\circ}\right.$ $S)$, and the black lines represent the variation in the average wind speed. The red lines show the three-year moving average variation. The dashed lines are the second-order polynomial curves.

have been continuously taken (Simmonds \& Jacka 1995; Ledley \& Huang 1997; Bromwich et al. 1998; Kwok \& Comiso 2002; Yuan 2004; Stammerjohn et al. 2008; Markle et al. 2012; Kohyama \& Hartmann 2016). ENSO is very important to changing sea-ice variability on the interannual time scale (Ledely \& Huang 1997), but only small fractions of the total ice variability can be explained by ENSO (Kohyama \& Hartmann 2016). In fact, in the interannual trends of the RSP area and the Nino3.4 index shown in Fig. 10, the interannual variability of the RSP areas is largely insignificant as compared to Nino3.4. The correlation coefficient is also low

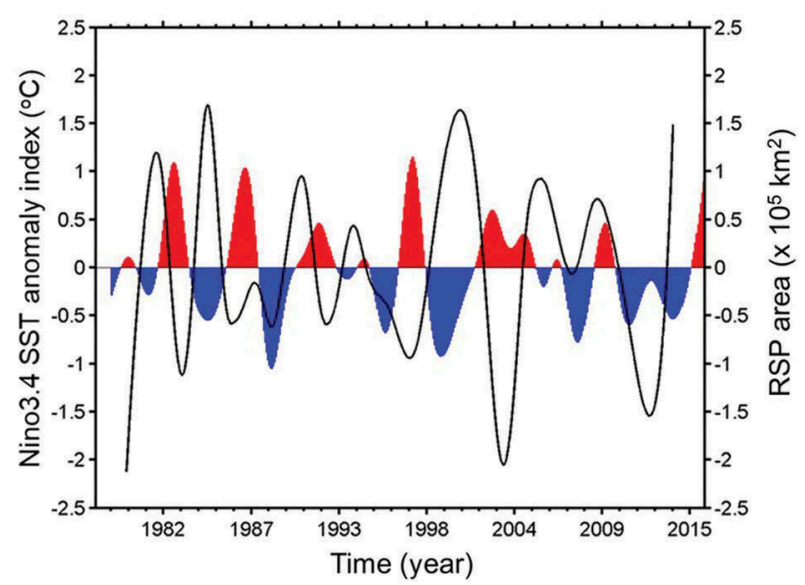

Figure 10. The time series of the sums of interannual components for the IMFs of the RSP areas (black solid line) and the Nino3.4 (bars). 
at -0.2 . However, when the residual mode is included, the correlation coefficient increases to about -0.5 . This suggests that the residual mode contributes most to their overall relation, and the long-term variation of RSP areas is likely to be considered as the major forcing to its change. Again, as shown in Fig. 8a, the overall pattern of the residual of the Nino3.4 index is similar to that of the trend of the RSP area as evidenced by such relation, but the timings of the turning points do not completely match: Nino3.4 leads the RSP area for about eight months. This lag indicates the time that the impact of ENSO is transferred to this region and more detailed research is needed.

\section{Variability of the RSP occurrence time}

With respect to polynya formation, the timing of polynya expansion is normally determined by yearly differences in environmental factors such as temperature and wind intensity (Bromwich et al. 1998). For instance, polynya expansion will occur earlier if the atmospheric temperature is higher than normal, and if the exposed sea surface experiences strong winds, the polynya will expand rapidly farther off the coast (Arrigo et al. 1998; Smith \& Barber 2007). The variation of the occurrence of the RSP determined by such timing is shown in Fig. 11. The aspects of variation of the RSP occurrence time slightly differ from that of the polynya area. The RSP occurrence time also had a large fluctuation, in common with the time series of the polynya area, but the maximum value appeared during the 2007/08 austral summer season and was recorded for 124 days. The occurrence time in that season was considerably longer than the occurrence times in other seasons and was two times longer than the mean occurrence time of approximately 61 days. On a long time scale, the trend of occurrence time increases abruptly owing to earlier polynya expansion and more delayed connectivity with the open ocean than previous polynyas (Fig. 12). The variation in the onset and connection of the RSP show the advanced

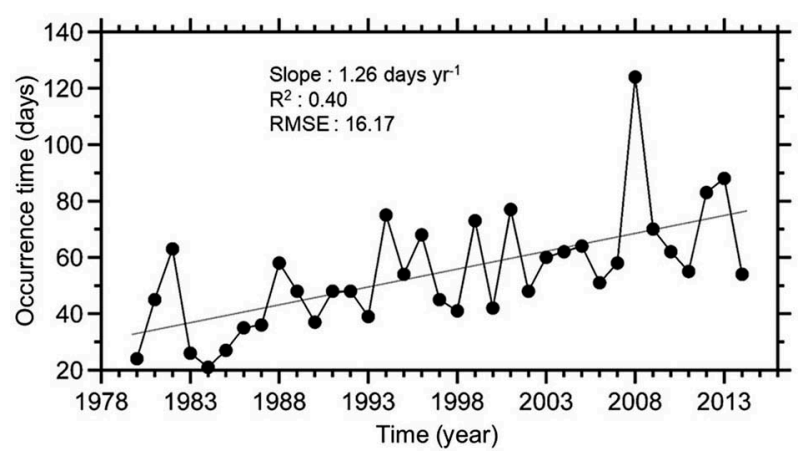

Figure 11. The variation of the occurrence of the RSP onset and connection timing. The solid line is the linear regression curve. onset and delayed connection to the open ocean. The linear trend of the onset and connection was about

-0.43 and +0.84 days per year, respectively. The fluctuation of the onset did not change largely, but the connection showed large fluctuation. Apparently, the occurrence time was mainly determined by the timing of the RSP's connection to the open ocean.

The nonlinear changes in the RSP occurrence time are shown in Fig. 13. Unlike the nonlinear trend (residual mode) of the RSP areas, the nonlinear trend of the RSP occurrence time indicates a consistent increase (no turning point and the functions increase very slowly). Therefore, the nonlinear trend might imply that the physical forcing driving the occurrence time differs from that causing the development of the polynya area. Because these data have a temporal resolution of one year, the high-frequency IMFs are insignificant and do not contain information on the detailed variation. The significant signals, c7-c12 (not shown), showed relatively high energy densities with similar magnitudes. The c7-c9 IMFs are the interannual components and had corresponding mean periods of $1.8,4.1$ and 7.2 years, respectively. The last three IMFs $(\mathrm{c} 10-\mathrm{c} 12)$ are the decadal variations, which have periods of more than 10 years. It indicates that the signal is well composed the original signal. Therefore, the residual is probable to investigate the long-term trend of polynya occurrence.

As the SAM index phase increased, colder and stronger than normal southerly winds blew over the Ross Sea. In turn, the southerly winds contributed to increasing sea-ice anomalies in the Ross Sea (Stammerjohn et al. 2008) and promoted the formation of the RSP (Nihashi \& Ohshima 2015). Therefore, to identify the relation between the trends for the RSP occurrence time and SAM index, their interannual, decadal and residual components were compared and are presented in Fig. 14. The interannual and decadal components have no significant relation. However, the residual component of the occurrence time, which is extracted using EEMD, was completely consistent with the residual component of the SAM index (correlation coefficient: +0.98 ). This is consistent with the statement of Matear et al. (2015) that sea-ice duration increases in the West Pacific sector, including the Ross Sea where SAM has an increasing trend like ENSO. From these results, we can infer that a positive SAM phase is likely to prolong the RSP occurrence time on long time scales, and a negative SAM can impact the shorter time of RSP development. As mentioned earlier, the increase in the SAM phase enhanced the southerly winds over the Ross Sea, and in turn, promoted the expansion of the polynya in concurrence with the vigorous sea-ice advection to the open ocean 


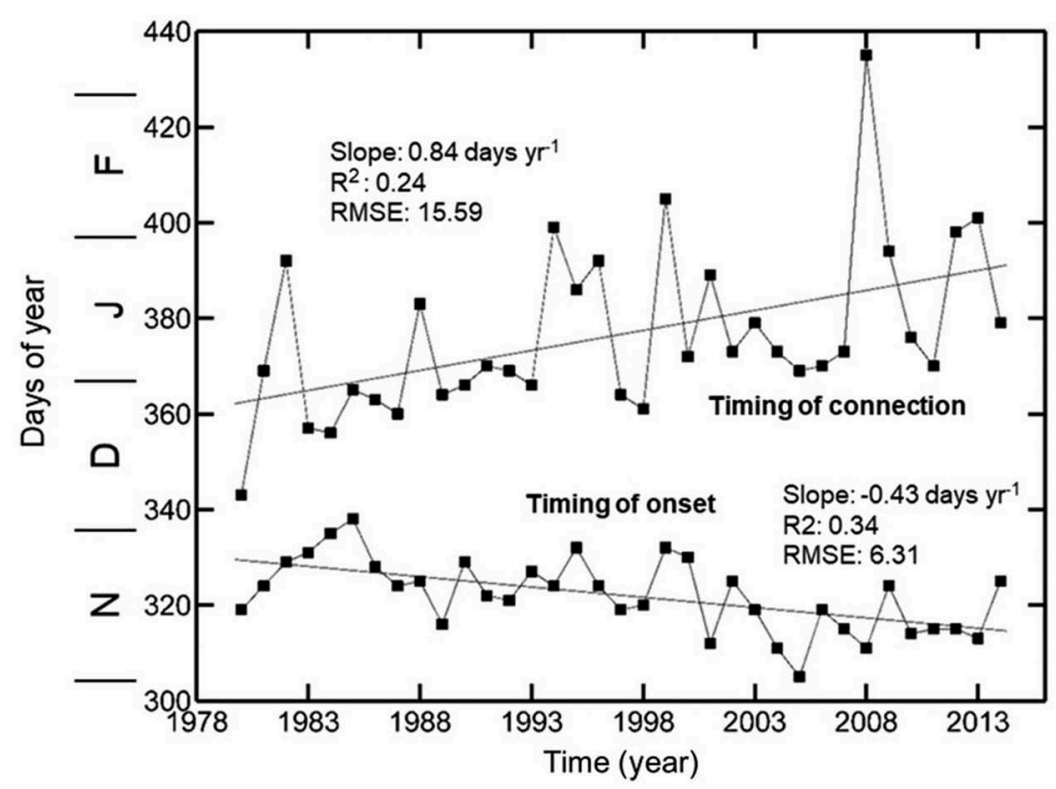

Figure 12. Variation of the onset and connection of the RSP. The black solid lines indicate the linear regression of the onset and connection, respectively.

(Arrigo et al. 1998; Smith \& Barber 2007). This means that the RSP occurrence time was eventually lengthened related to the recent strong positive SAM phase. Although both the interannual and decadal components have no significant relation, their residuals have a close relation. The energy density for the occurrence time in the residuals plays a positive and more significant role (y axis) in the increase in the RSP occurrence time than other components. Therefore, the nonlinear variability of SAM with the increase is likely to contribute to the earlier onset of polynya expansion and the delayed connectivity associated with the increase in sea-ice coverage over the entire Ross Sea.

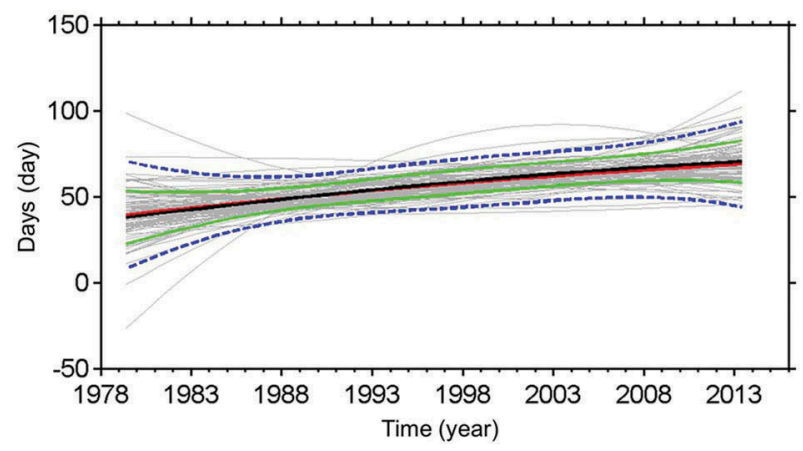

Figure 13. The residual mode of the RSP occurrences with bootstrap simulations (100 iterations) for the significance test. The grey solid lines indicate the simulated individual trend and the red and black lines are trends of artificial mean and original data, respectively. The standard deviation and the 95\% confidence intervals are expressed as the green solid lines and blue dashed lines, respectively.

\section{Summary}

In this study, the trends in the variability of RSP areas and occurrence time were investigated using the EEMD decomposition method. In addition, the relation between the RSP characteristics and climate state through the Nino3.4 and SAM indices was analysed. The findings of this study are as follows.

The nonlinear trend in the RSP areas between 1979 and 2014 had a turning point during the early 1990s. When considering the nonlinear trends of the meridional and zonal wind components together (as the ratio of the residual modes of the meridional and zonal winds), the ratio was consistent with the trend in the variability of the RSP areas (correlation coefficient: +0.98 ). This means

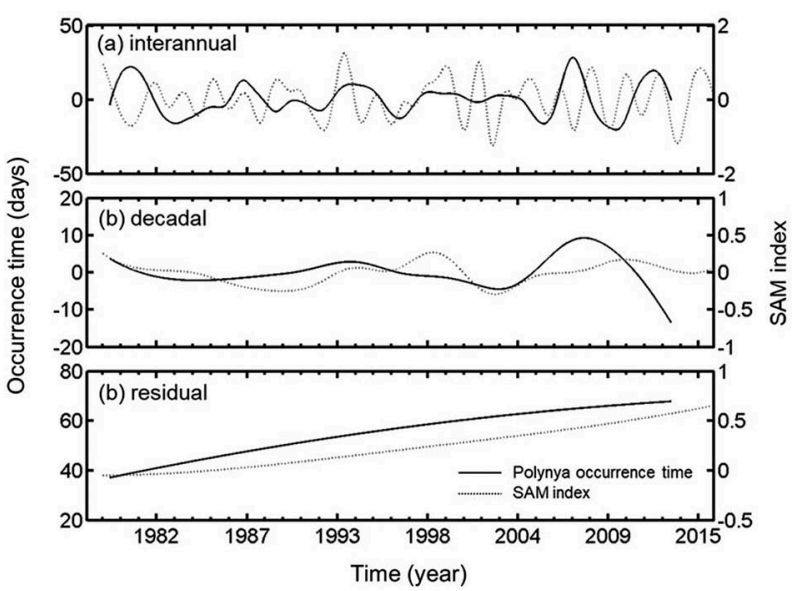

Figure 14. (a) The interannual, and (b) decadal variations of IMFs, and (c) the residuals of the RSP occurrence time (solid line) and the SAM index (dashed line). The significance of the correlation coefficients was tested using the student's t-test $(p<0.05)$. 
that the meridional component is more closely related with the expansion of RSP than the zonal component of winds.

ENSO with strong interannual variability is not correlated with the interannual variation of the RSP area. However, the variability of the RSP areas is highly correlated with the variability of atmospheric forcing on a long (more than decadal) time scale. Such atmospheric forcing is likely to be attributed to the long-term factors simultaneously controlling the Nino3.4 index. This can be demonstrated by the residual of Nino3.4 also having turning points during 1992/93.

Although the RSP area changes have a nonlinear trend with the specific timing of the turning point, the RSP occurrence time has gradually increased from 1979 to 2014 without a phase shift. The different nonlinearity features between them are likely to be the result of different responding forces to either regional conditions (e.g., SAM) or teleconnections (e.g., ENSO events).

Regardless of the interannual and decadal components, the variability of the RSP occurrence is highly correlated with the long-term trend of SAM. The earlier onset of RSP expansion and the delayed connection with the Southern Ocean is likely to be related to changes in the physical factors, affecting the development of the RSP, associated with the recent increase of the SAM index.

\section{Disclosure statement}

No potential conflict of interest was reported by the authors.

\section{Funding}

This study was carried out with the support of the Satellite Remote Sensing on West Antarctic Ocean Research (STAR) project (no. PE14040) and was a part of the project entitled Ecosystem Structure and Function of Marine Protected Area (MPA) in Antarctica (PM17060) funded by the Ministry of Oceans and Fisheries, Korea.

\section{ORCID}

Autumn Kidwell (D) http://orcid.org/0000-0003-0623-322X

\section{References}

Arrigo K.R. \& Van Dijken G.L. 2003a. Phytoplankton dynamics within 37 Antarctic coastal polynya systems. Journal of Geophysical Research-Oceans 108, article no. 3271, doi: 10.1029/2002JC001739.

Arrigo K.R. \& Van Dijken G.L. 2003b. Impact of iceberg C19 on Ross Sea primary production. Geophysical Research Letters 30, article no. 1836, doi: 10.1029/ 2003 GL017721.

Arrigo K.R., Van Dijken G.L., Ainley D.G., Fahnestock M. A. \& Markus T. 2002. Ecological impact of a large Antarctic iceberg. Geophysical Research Letters 29, article no. 1104 , doi: 10.1029/2001GL014160.
Arrigo K.R., Weiss A.M. \& Smith W.O. 1998. Physical forcing of phytoplankton dynamics in the southwestern Ross Sea. Journal of Geophysical Research-Oceans 103, 1007-1021.

Bromwich D., Liu Z., Rogers A.N. \& Van Woert M.L. 1998. Winter atmospheric forcing of the Ross Sea polynya. In S. S. Jacobs \& R.F. Weiss (eds.): Ocean, ice, and atmosphere: interactions at the Antarctic continental margin. Pp. 101133. Washington, DC: American Geophysical Union.

Capparelli V., Franzke C., Vecchio A., Freeman M.P., Watkins N.W. \& Carbone V. 2013. A spatiotemporal analysis of US station temperature trends over the last century. Journal of Geophysical Research-Atmospheres 118, 7427-7434.

Cavalieri D., Parkinson C., Gloersen P. \& Zwally H.J. 1996. Sea ice concentrations from Nimbus-7 SMMR and DMSP SSM/I-SSMIS passive microwave data, version 1 (19882014). Boulder, CO: NASA National Snow and Ice Data Center Distributed Active Archive Center. Accessed on the internet at http://nsidc.org/data/nsidc-0051 on 15 January 2015, doi: 10.5067/8GQ8LZQVL0VL.

Comiso J.C. \& Gordon A.L. 1998. Inter-annual variability in summer sea ice minimum, coastal polynyas and bottom water formation in the Weddell Sea. In M.O. Jeffries (ed): Antarctic sea ice: physical processes, interactions and variability. Pp. 293-315. Washington DC: American Geophysical Union.

Comiso J.C., Kwok R., Martin S. \& Gordon A.L. 2011. Variability and trends in sea ice extent and ice production in the Ross Sea. Journal of Geophysical ResearchOceans 116, article no. 04021, doi: 10.1029/ 2010JC006391.

Drucker R., Martin S. \& Kwok R. 2011. Sea ice production and export from coastal polynyas in the Weddell and Ross seas. Geophysical Research Letters 38, L17502, doi: 10.1029/2011GL048668.

Ezer T. \& Corlett W.B. 2012. Is sea level rise accelerating in the Chesapeake Bay? A demonstration of a novel new approach for analyzing sea level data. Geophysical Research Letters 39, L19605, doi: 10.1029/ 2012GL053435.

Franzke C. 2012. Nonlinear trends, long-range dependence, and climate noise properties of surface temperature. Journal of Climate 25, 4172-4183.

Huang N.E., Shen Z., Long S.R., Wu M.L.C., Shih H.H., Zheng Q.N., Yen N.C., Tung C.C. \& Liu H.H. 1998. The empirical mode decomposition and the Hilbert spectrum for nonlinear and non-stationary time series analysis. Proceedings of the Royal Society London Series A 454, 903-995.

Jacobs S.S. 2004. Bottom water production and its links with the thermohaline circulation. Antarctic Science 16, 427-437.

Jacobs S.S. \& Comiso J.C. 1989. Sea ice and oceanic processes on the Ross Sea continental shelf. Journal of Geophysical Research-Oceans 94, 18195-18211.

Jo Y.H., Breaker L.C., Tseng Y.H. \& Yeh S.W. 2014. A temporal multiscale analysis of the waters off the east coast of South Korea over the past four decades. Terrestrial, Atmospheric and Oceanic Sciences 24, 415-434.

Jo Y.H., Kim H.C., Son S. \& Kim D. 2016. Analysis of the timing of phase changes in the chlorophyll concentration in the East/Japan Sea. Continental Shelf Research $127,1-11$.

Kalnay E., Kanamitsu M., Kistler R., Collins W., Deaven D., Gandin L. \& Zhu Y. 1996. The NCEP/NCAR 40-year reanalysis project. Bulletin of the American Meteorological Society 77, 437-471. 
Kistler R., Collins W., Saha S., White G., Woollen J., Kalnay E. \& Van Den Dool H. 2001. The NCEP-NCAR 50-year reanalysis: monthly means $\mathrm{CD}-\mathrm{ROM}$ and documentation. Bulletin of the American Meteorological Society 82, 247-267.

Kohyama T. \& Hartmann D.L. 2016. Antarctic sea ice response to weather and climate modes of variability. Journal of Climate 29, 721-741.

Kwok R. \& Comiso J.C. 2002. Spatial patterns of variability in Antarctic surface temperature: connections to the Southern Hemisphere annular mode and the Southern Oscillation. Geophysical Research Letters 29, article no. 1705, doi: 10.1029/2002GL015415.

Ledley T.S. \& Huang Z. 1997. A possible ENSO signal in the Ross Sea. Geophysical Research Letters 24, 3253-3256.

Lee H.S. 2013. Estimation of extreme sea levels along the Bangladesh coast due to storm surge and sea level rise using EEMD and EVA. Journal of Geophysical Research -Oceans 118, 4273-4285.

Liu J., Curry J.A. \& Martinson D.G. 2004. Interpretation of recent Antarctic sea ice variability. Geophysical Research Letters 31, L02205, doi: 10.1029/2003GL018732.

Markle B.R., Bertler N.A.N., Sinclair K.E. \& Sneed S.B. 2012. Synoptic variability in the Ross Sea region, Antarctica, as seen from back-trajectory modeling and ice core analysis. Journal of Geophysical Research-Atmospheres 117, D02113, doi: 10.1029/ 2011JD016437.

Martin S., Drucker R.S. \& Kwok R. 2007. The areas and ice production of the western and central Ross Sea polynyas, 1992-2002, and their relation to the B-15 and C-19 iceberg events of 2000 and 2002. Journal of Marine Systems 68, 201-214.

Matear R.J., O'Kane T.J., Risbey J.S. \& Chamberlain M. 2015. Sources of heterogeneous variability and trends in Antarctic sea-ice. Nature Communications 6, article no. 8656, doi: 10.1038/ncomms9656.

Montes-Hugo M.A. \& Yuan X. 2012. Climate patterns and phytoplankton dynamics in Antarctic latent heat polynyas. Journal of Geophysical Research-Oceans 117, C05031, doi: 10.1029/2010JC006597.

Mudelsee M. 2010. Climate time series analysis: classical statistical and bootstrap methods. Dordrecht: Springer.

Nihashi S. \& Ohshima K.I. 2015. Circumpolar mapping of Antarctic coastal polynyas and landfast sea ice: relationship and variability. Journal of Climate 28, 3650-3670.

NSIDC 2015. Geocoordinate and pixel-area tools. Accessed on the internet at https://nsidc.org/data/polar-stereo/ tools_geo_pixel.html on 15 January 2015.

Parish T.R. \& Bromwich D.H. 1987. The surface windfield over the Antarctic ice sheets. Nature 328, 51-54.

Parkinson C.L. \& Cavalieri D.J. 2012. Antarctic sea ice variability and trends, 1979-2010. The Cryosphere 6, 871-880.

Petrelli P., Bindoff N.L. \& Bergamasco A. 2008. The sea ice dynamics of Terra Nova Bay and Ross Ice Shelf polynyas during a spring and winter simulation. Journal of Geophysical Research-Oceans 113, C09003, doi: 10.1029/2006JC004048.

Robinson N.J. \& Williams M.J.M. 2012. Iceberg-induced changes to polynya operation and regional oceanography in the southern Ross Sea, Antarctica, from in situ observations. Antarctic Science 24, 514-526.

Rusciano E., Budillon G., Fusco G. \& Spezie G. 2013. Evidence of atmosphere-sea ice-ocean coupling in the Terra Nova Bay polynya (Ross Sea-Antarctica). Continental Shelf Research 61, 112-124.

Sea Ice Atlas 2015. Common terms used in sea ice research. Accessed on the internet at http://seaiceatlas.snap.uaf. edu/glossary on 15 January 2015.

Simmonds I. \& Jacka T.H. 1995. Relationships between the inter-annual variability of Antarctic sea ice and the Southern Oscillation. Journal of Climate 8, 637-647.

Smith W.O., Ainley D.G. \& Cattaneo-Vietti R. 2007. Trophic interactions within the Ross Sea continental shelf ecosystem. Philosophical Transactions of the Royal Society of London B: Biological Sciences 362, 95-111.

Smith W.O. \& Barber D.G. 2007. Polynyas: windows to the world. Amsterdam: Elsevier.

Stammerjohn S.E., Martinson D.G., Smith R.C., Yuan X. \& Rind D. 2008. Trends in Antarctic annual sea ice retreat and advance and their relation to El Niño-Southern Oscillation and Southern Annular Mode variability. Journal of Geophysical Research-Oceans 113, C03S90, doi: 10.1029/2007JC004269.

Turner J., Comiso J.C., Marshall G.J., Lachlan-Cope T.A., Bracegirdle T., Maksym T., Meredith M.P., Wang Z. \& Orr A. 2009. Non-annular atmospheric circulation change induced by stratospheric ozone depletion and its role in the recent increase of Antarctic sea ice extent. Geophysical Research Letters 36, L08502, doi: 10.1029/ 2009 GL037524.

Van Woert M.L. 1999. Wintertime dynamics of the Terra Nova Bay polynya. Journal of Geophysical ResearchOceans 104, 7753-7769.

Van Woert M.L., Johnson E.S., Langone L., Worthen D.L., Monaghan A., Bromwich D.H., Meloni R. \& Dunbar R. B. 2003. The Ross Sea circulation during the 1990s. In G.R. Ditullio \& R.B. Dunbar (eds.): Biogeochemistry of the Ross Sea. Pp. 5-34. Washington DC: American Geophysical Union.

Wu Z. \& Huang N.E. 2004. A study of the characteristics of white noise using the empirical mode decomposition method. Proceedings of the Royal Society of London A: Mathematical, Physical and Engineering Sciences 460, 1597-1611.

Wu Z. \& Huang N.E. 2009. Ensemble empirical mode decomposition: a noise-assisted data analysis method. Advances in Adaptive Data Analysis 1, 1-41.

Wu Z., Huang N.E. \& Chen X. 2009. The multi-dimensional ensemble empirical mode decomposition method. Advances in Adaptive Data Analysis 1, 339-372.

Yuan X.J. 2004. ENSO-related impacts on Antarctic sea ice: a synthesis of phenomenon and mechanisms. Antarctic Science 16, 415-425.

Zwally H.J., Comiso J.C. \& Gordon A.L. 1985. Antarctic offshore leads and polynyas and oceanographic effects. In S.S. Jacobs (ed.): Oceanology of the Antarctic continental shelf. Pp. 203-226. Washington DC: American Geophysical Union. 